\title{
Exogenous and endogenous control of attention: The effect of visual onsets and offsets
}

\author{
JAN THEEUWES \\ TNO Institute for Perception, Soesterberg, The Netherlands
}

\begin{abstract}
Two experiments were carried out to investigate the relation between exogenous and endogenous control of visual attention. Subjects searched for a target letter among three nontarget letters that were positioned on an imaginary circle around a fixation point. At different cue-display intervals, a centrally located arrowhead cue reliably indicated the location of the target letter. At different SOAs, a peripheral line segment near one of the letters was either abruptly switched on (Experiment 1) or abruptly switched off (Experiment 2). Presenting the central arrowhead after display onset prevents attention from being focused in advance on the critical location. In this unfocused attentional state, both onset and offset transients attracted attention. When the central arrowhead was available in advance, the focusing of attention prior to display onset precluded attention attraction to the location of the onset or offset transient. Contrary to an offset transient, an onset transient presented at the attended location disrupted performance, indicating that an onset within the spotlight of attention attracts attention. The results are reconciled by means of the zoom-lens theory of attention, suggesting that outside the focus of attention, abrupt transients are not capable of attracting attention. Since the size of the zoom lens is under voluntary control, it can be argued that transients do not fulfill the intentionality criterion of automaticity.
\end{abstract}

It is well known that selective visual attention can be voluntarily directed to nonfixated locations in visual space. As a metaphor, this endogenous control of visual selectivity has been described as a spotlight (see, e.g., Broadbent, 1982; Posner, Snyder, \& Davidson, 1980) or a zoom lens, suggesting that attention can vary from a uniform distribution over the entire field to a highly focused concentration (Eriksen \& Yeh, 1985). Endogenous attentional selectivity can be inferred from performance differences in detecting signals at expected (attended) and unexpected (unattended) spatial locations (Posner, 1980; Posner et al., 1980). Typically, a central cue (e.g., an arrowhead) pointing to the likely target location can direct attention to that location. Relative to a neutral cue, spatially valid cues result in benefits, measured in shorter latencies and less errors, and spatially invalid cues result in costs, measured in longer latencies and more errors.

Alternatively, attention can be controlled by external factors. Yantis and Jonides (1984) demonstrated that the visual system is selectively sensitive to an abrupt onset of visual stimuli. Their visual search experiments showed that an item with abrupt onset was always processed first, resulting in fast identification of onset stimuli compared to no-onset stimuli. These results were interpreted as evi-

This study was supported in part by the Institute for Road Safety Research SWOV. I would like to thank Johan B. J. Riemersma, A. F. Sanders, Steven Yantis, and an anonymous reviewer for helpful comments and suggestions on an earlier draft of the article. Correspondence concerning this article should be addressed to Jan Theeuwes, TNO Institute for Perception, P.O. Box 23, 3769 ZG Soesterberg, The Netherlands. dence that abrupt onset exerts control over the allocation of attention such that it draws attention to its location. Because the number of simultaneous no-onset items did not affect reaction time, it was claimed that abrupt onset has an automatic effect as it satisfies the load or interference criterion of automaticity (e.g., Jonides, Naveh-Benjamin, \& Palmer, 1985; LaBerge, 1981; Neumann, 1984; Yantis \& Jonides, 1990). This criterion states that "automatic processes operate without capacity and they thus neither suffer nor cause interference" (Neumann, 1984, p. 257).

Jonides and Yantis (1988; Yantis \& Jonides, 1984) have demonstrated that stimulus onset transients are capable of attracting attention. Miller (1989) showed that attention is not controlled by abrupt onset per se, but that all abrupt changes in the visual field (i.e., visual transients), are capable of attracting attention. Miller's experiments showed that an abrupt offset transient has indeed some power to attract attention.

Jonides (1981) used peripheral cues with abrupt onsets to indicate likely target positions and showed that such cues elicit an exogenous shift of attention to the indicated location. Jonides (1981) found that a concurrent memoryload task affected only endogenous orienting in response to a central cue, whereas exogenous orienting in response to a peripheral cue was not affected. Jonides claimed that the attention-capturing power of the peripheral cue was unaffected by the increased demands on processing capacity, a finding that satisfies the load criterion of automaticity. In his second experiment, Jonides (1981) showed that subjects who were told to ignore either a central or a peripheral cue were unable to ignore the peripheral cue. This result indicated that one cannot suppress orienting 
to a peripheral cue. Because the attention-capturing property of a peripheral cue seems not to be subject to voluntary control, it satisfies the intentionality criterion of automaticity (Jonides et al., 1985; LaBerge, 1981; Yantis \& Jonides, 1990). This criterion states that "automatic processes are under the control of stimulation rather than under the control of the intentions (strategies, expectancies, plans) of the person" (Neumann, 1984, p. 258).

Although there seems to be convincing evidence that abrupt onset transients satisfy the load criterion of automaticity (Yantis \& Jonides, 1984), it remains unclear whether abrupt onsets are also automatic in the sense of the intentionality criterion. If attention is uniformly distributed over the entire field, it is likely that an abrupt onset captures attention that cannot be controlled by the subject. On the other hand, if attention is highly focused on a particular location, abrupt onsets may cease to attract attention. The latter result would indicate that abrupt onsets outside the spotlight of attention cannot capture attention, suggesting that abrupt onsets do not always fulfill the intentionality criterion of automaticity.

This question was recently addressed by Müller and Rabbitt (1989) in a study in which subjects were instructed to attend a location cued by a central arrowhead. At various moments after the appearance of the arrowhead, a peripheral box surrounding one of the four possible target locations flashed for $50 \mathrm{msec}$. Although voluntary allocation modulated the extent to which a peripheral flash captured attention, Müller and Rabbitt concluded that allocating attention to a location could not prevent a shift of attention to the abruptly changing flash. Clearly, these results provide evidence for the claim that abrupt onsets are genuinely automatic in the sense of the intentionality criterion.

Recently, however, Yantis and Jonides (1990) reported contrasting results. In their experiments, an abrupt onset did not overcome the voluntary allocation of attention. When attention was allocated to a valid location, reaction time to that location was not affected by the presence of an abrupt onset somewhere else in the stimulus field. It was concluded that abrupt onsets do not fulfill the intentionality criterion of automaticity, suggesting that abrupt onsets are only partially automatic in the sense of Kahneman and Treisman (1984).

Although these studies yielded contrasting results, they differed in a number of ways. Müller and Rabbitt (1989) used a long cue-to-target stimulus onset asynchrony (SOA) $(600-1,200 \mathrm{msec})$ and a relatively low cue validity (50\%). As has been argued by Yantis and Jonides (1990), these conditions might have precluded full attentional focusing, permitting attentional capturing by the flashing boxes on some trials. In addition, the results might have been contaminated because there was no control for stimulus offset of both the central and the peripheral cue. It has been argued that offsets also have the ability to capture attention (Miller, 1989).
The procedure employed by Yantis and Jonides (1990) also differed slightly from that of a typical cuing paradigm. Rather than having an exogenous cue with a clear onset, their stimulus field always contained one item with onset among three items without onset, which were produced by way of the no-onset procedure developed by Todd and Van Gelder (1979). In this procedure, stimuli with camouflaging line segments are presented in advance of the target display. At the moment of presentation of the stimulus field, the camouflaging line segments are removed so that the stimulus field appears without any localized abrupt onset. In Yantis and Jonides's (1990) studies, simultaneous with the disappearing line segments, one item was presented at an empty location leading to an abrupt onset at one of the stimulus field locations. Despite the elegance of this procedure, it does not permit the analysis of the time course of exogenous activation, because the abrupt onset is linked to the presentation of the whole stimulus field.

It is also worth noting that the experiments of Yantis and Jonides (1990) contain a confound induced by the nooffset paradigm. In their procedure, subjects intentionally focused attention on the potential target location. When the stimulus field was presented, one item appeared with abrupt onset, while the remaining items were presented by removing the camouflaging line segments. Since these events happened simultaneously, it is possible that subjects were capable of maintaining voluntary allocation of attention to the likely target position because of stimulus offset at the attended location. Since offsets also have the power of attracting attention (Miller, 1989), it might well be that the stimulus onset in Yantis and Jonides's (1990) study did not capture attention, because this was prevented by competing offsets at the attended location. Obviously, this interpretation would severely limit Yantis and Jonides's conclusions.

The two experiments to be reported here were designed to test the intentionality criterion of visual transients. This was done by analyzing the time course of facilitation or inhibition of a central cue pointing to the target position relative to a peripheral transient that was randomly associated with the target location. If a peripheral transient captures attention even when subjects focus their attention on some particular location, then the transient satisfies the intentionality criterion, which states that capture cannot be prevented. According to Kahneman and Treisman's (1984) levels of automaticity, abrupt transients would fulfill the criteria of strongly automatic perceptual processing, suggesting that processing is neither facilitated by focusing attention on a stimulus, nor impaired by diverting attention from it (p. 42). Alternatively, if focusing a location in the visual field precludes abrupt transients from disrupting performance, then they cannot be considered as strongly automatic. Such a result would suggest that events outside the spotlight of attention are not capable of breaking through and therefore do not disrupt processing at the attended location. In Experi- 
ment 1 , the effect of abrupt onset transients was examined; Experiment 2 was undertaken to replicate Experiment 1 with abrupt offset transients.

\section{EXPERIMENT 1}

Experiment 1 was carried out to investigate whether stimulus onset disrupts processing when attention is fully focused on a particular location. In view of the discussed difficulties with earlier studies, there was an exact control of stimulus onset and offset of both the central cue and the peripheral bar marker. In addition to the relatively brief central cue-to-display SOA of $200 \mathrm{msec}$ used by Yantis and Jonides (1990), the present study included a long SOA of $600 \mathrm{msec}$, since it has been claimed that optimal attentional focusing is obtained with relatively long SOAs (Müller \& Findley, 1988; Müller \& Rabbitt, 1989).

On each trial, subjects searched for a target letter among three nontarget letters, which were positioned on an imaginary circle around the fixation point. All letters were presented by means of the no-onset procedure developed by Todd and Van Gelder (1979). With variable central cue-to-display SOAs ( $-600,-300$, or $200 \mathrm{msec}$ ), a central arrowhead with gradual onset reliably indicated the location of a critical letter. ${ }^{1}$ Because the central cue was always valid, attentional focusing toward the cued location is supposed to be optimal (Yantis \& Jonides, 1990, Experiment 3). At variable peripheral marker-to-display SOAs $(-160,-80,0,80 \mathrm{msec}$, or none) a line segment near one of the letters was abruptly switched on (cf. Eriksen \& Hoffman, 1973). The location of the peripheral onset was randomly associated with the location of the critical letter. In this way, the only nonsymmetric abrupt change in the visual display was the peripheral onset.

The strong automaticity hypothesis claims that, regardless of the subject's state, an abrupt onset at a noncued location should capture attention and slow the reaction to the critical letter. Alternatively, if voluntary allocation of attention can overrule the attention attraction of the peripheral onset transient, this transient should not affect performance.

\section{Method}

Task and Stimuli. The trial events are shown in Figure 1. The stimulus display and task were similar to those of Yantis and Jonides (1990). In a trial, five frames were presented in successive order. The first frame contained a fixation dot $\left(.2^{\circ}\right)$ at the center of the visual field for $500 \mathrm{msec}$, which served as a warning for the beginning of the trial. Along with the fixation dot, the second frame contained four figure-eight premasks, which were presented $4.2^{\circ}$ from the center fixation dot at the ends of an imaginary plus sign. The premasks $\left(.9^{\circ} \times .6^{\circ}\right)$ were always presented $1,000 \mathrm{msec}$ before display onset. The third frame displayed a triangular arrowhead of $1.4^{\circ}$ in length and $.8^{\circ}$ in width at the center of fixation. This arrowhead served as a central cue that reliably indicated (cue validity, $100 \%$ ) the position of the critical letter. In order to minimize possible attention-capturing effects of abrupt onset, the arrowhead was gradually presented. The luminance of the arrowhead increased stepwise for $100 \mathrm{msec}$, with increments situated $20 \mathrm{msec}$ apart. The beginning of the gradual arrowhead onset started at one of the three possible SOAs: $-600,-300$, or $200 \mathrm{msec}$. Along with premasks and the central cue, the fourth frame contained the peripheral onset, which was a line segment $\left(.3^{\circ} \times .6^{\circ}\right)$ presented on the outside of the imaginary plus sign. The separation of the nearest contours of peripheral onset cue and stimuli was $.5^{\circ}$ (cf. Eriksen \& Hoffman, 1973). Apart from the control condition in which there was no peripheral onset, there were four possible peripheral markerto-display SOAs: $-160,-80,0$, or $80 \mathrm{msec}$. The fifth frame displayed the stimulus field in which, along with the cue and the peripheral marker, the letters were presented. These letters were $E, H$, $P, S$, and $U$, which were obtained by removing two line segments of each of the seven-segment figure-eight premasks. At a viewing

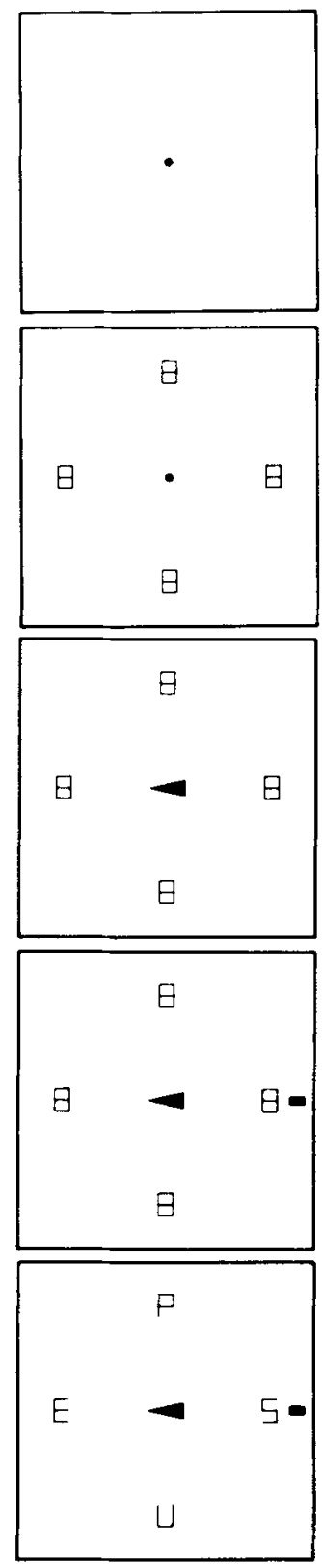

Figure 1. Example of trial events. The central arrow points with $100 \%$ validity to the location of the target (in this case, the letter $E$ ). The line segment with abrupt onset is positioned randomly with various SOAs near one of the four letters. 
distance of $90 \mathrm{~cm}$, the letters subtended $.9^{\circ}$ in height and $.6^{\circ}$ in width, and they were $4.5^{\circ}$ apart, center to center. The target letters to be discriminated were $\mathrm{E}$ or $\mathrm{H}$, corresponding, respectively, to a left and a right response key. These keys were pressed by the thumb of the left or the right hand, respectively. Each display contained one target letter ( $\mathrm{E}$ or $\mathrm{H}$ ) among three nontarget letters $(\mathrm{P}, \mathrm{S}, \mathrm{U})$. After responding, the display was extinguished for $500 \mathrm{msec}$.

Apparatus. An S-R interface with external clocks (accuracy, $1 \mathrm{msec}$ ) connected to an IBM AT-3 with video-digitizer (Matrox) controlled the timing of the events, generated video pictures, and recorded reaction times. The response panel, $45^{\circ}$ tilted, consisted of a left and a right response key $(1 \times 1 \mathrm{~cm})$, which were mounted $5.5 \mathrm{~cm}$ apart. When an error was made, a warning tone was generated by an audio generator. The stimuli appeared on a $35 \times 23 \mathrm{~cm}$ TV monitor (Barco, CDCT 2/51) and had a luminance of $10.0 \mathrm{~cd} / \mathrm{m}^{2}$ on a black screen of $0.5 \mathrm{~cd} / \mathrm{m}^{2}$.

The subjects were tested in a sound-attenuated, dimly lit $2 \times 2 \times 2$ m cubicle (Amplisilent) with their heads resting on a chinrest adjusted to a comfortable height. The TV monitor was located at eye level, $90 \mathrm{~cm}$ from the chinrest. An intercom was used for communication with the subject. An infrared light and camera directed at the subject's eyes provided on-line information about eye movements.

Subjects. Twenty-four subjects ranging in age from 18 to 26 years participated in the experiment. Eight subjects were randomly assigned to each of the three SOA central cue conditions. All had normal or corrected-to-normal vision, were right-handed, and were paid for their participation.

Experimental Design and Procedure. The central cue-to-display SOA condition $(-600,-300,200 \mathrm{msec})$ was varied between subjects. The peripheral onset-to-display SOA condition $(-160,-80$, $0,80 \mathrm{msec}$ ), including the control condition without peripheral onset, was varied within subjects and blocks. Within each block, the target was an $\mathrm{E}$ on half of the trials and an $\mathrm{H}$ on the other half. The target letter appeared at each location equally often, implying that each location was indicated by the central cue equally often. On $25 \%$ of the trials, the peripheral onset appeared near the target location (trial type: target location); on $75 \%$ of the trials, the peripheral onset appeared near one of the nontarget locations (trial type: nontarget location).

Each subject participated in nine experimental sessions. An experimental session lasted approximately $12 \mathrm{~min}$ and consisted of 160 trials, with a short break after 80 trials. In order to avoid warmup effects, each block started with 3 dummy trials. To rule out aftereffects of errors, a wrong response was followed by a randomly chosen dummy trial, which was not recorded.
Before the start of the experiment, the subjects were instructed to search for an $\mathrm{E}$ or an $\mathrm{H}$ and press the appropriate response keys with their thumbs, which were resting on the response keys. It was emphasized to the subjects that they should fixate the central dot and not move their eyes at any time during the experiment. ${ }^{2}$ To ensure that subjects followed the instructions, eye movements were monitored on-line by means of an infrared camera during practice sessions. The subjects were asked to use the central cue to direct attention to the indicated location. It was stressed that a steady fixation and the use of the central cue would reduce their reaction times and make the task easier. The subjects were instructed to respond as fast as possible while keeping their errors to a minimum. Each subject had one practice session of 160 trials.

\section{Results}

Mean response times were calculated for each subject for each of the factor combinations (trial type, SOA peripheral onset, SOA central cue). Mean correct RTs are shown in Figure 2. Separate analyses of variance (ANOVAs) were performed on the three central cue SOA conditions.

For the central cue SOA of $200 \mathrm{msec}$, reliable effects were found for both peripheral onset SOA $[F(3,21)=$ $14.9, p<.01]$ and trial type $[F(1,7)=10.3, p<.05]$. In addition, the interaction between these variables was reliable $[F(3,21)=7.2, p<.01]$. Since the central cue starts to appear $200 \mathrm{msec}$ after display onset, attention cannot be focused in advance on the critical location. As is evident in Figure 2, under these circumstances the peripheral onset captures attention since there is a reliable lower mean reaction time for the trials in which there is a peripheral onset near the target location relative to the trials in which there is an onset near a location containing a nontarget. Comparison of the means of the different peripheral onset SOA conditions for each trial type with the control showed reliable differences between the conditions with an onset near the nontarget with the control [Dunnett's $t$ tests, $t(28)>4.43, p<.01$-except for the SOA of $-80 \mathrm{msec}, t(28)=1.92]$. In addition, the conditions in which the onset appeared 160 or $80 \mathrm{msec}$ before display onset near the target location differed significantly from the control condition $[t(28)>2.56$,

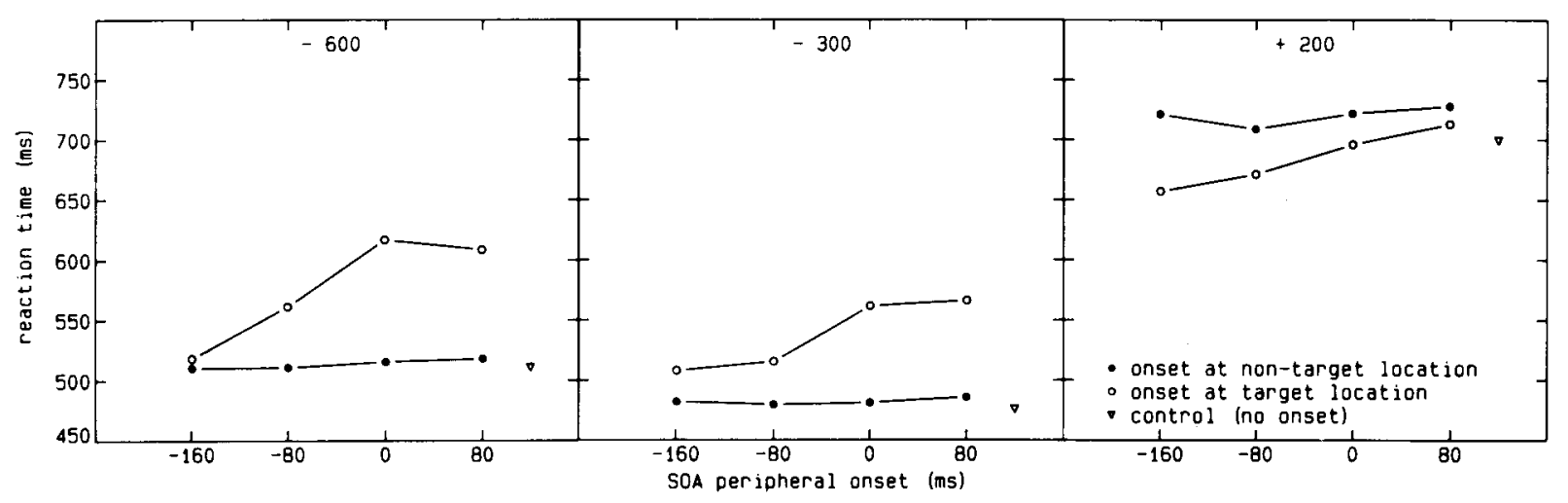

Figure 2. Mean reaction time for different trial types (onset near nontarget, onset near target, control) as a function of peripheral onset-to-display SOA for the central cue-display intervals of $-600 \mathrm{msec}$ (left panel), $-300 \mathrm{msec}$ (middle panel), and $200 \mathrm{msec}$ (right panel). 
$p<.05]$. These results suggest that, relative to the control condition, the peripheral onset produced fast responding when the onset appeared near the target location and slow responding when the onset appeared near a nontarget location. This finding is important, since it shows that even when there is no benefit to intentionally attend to the peripheral onset, the onset attracts attention.

For the condition with the central cue SOA of $-600 \mathrm{msec}$, there were significant effects for both peripheral onset SOA $[F(3,21)=16.8, p<.01]$ and trial type $[F(1,7)=66.9, p<.01]$. In addition, there was an interaction between these variables $[F(3,21)=16.5, p<.01]$. A similar pattern of results was found for the peripheral onset SOA of $-300 \mathrm{msec}$. Again, peripheral onset and trial type were significant $[F(3,21)=16.5, p<.01$, and $F(1,7)=39.7, p<.01$, respectively]. The interaction between these variables was also reliable $[F(3,21)=9.7$, $p<.01]$. As is clear from Figure 2, relative to the SOA 200-msec condition, the effects are reversed, revealing that a peripheral onset only interferes when occurring at the attended location. Subsequent Newman-Keuls tests (all $p s<.05$ ) showed that for the central SOA of $-600 \mathrm{msec}$, all levels of peripheral onset SOAs at nontarget location and the peripheral SOA of $-160 \mathrm{msec}$ at target location differed significantly from the other peripheral onset SOAs at target location. The same pattern of results was found for the central SOA of $-300 \mathrm{msec}$, except that there was no reliable difference anymore between SOA -80 -msec conditions. These results suggest that the distracting effects of a peripheral onset are reduced when it clearly occurs before display onset.

The lack of any difference between the control condition and conditions in which the onset occurs at the nonattended location [Dunnett's $t$ tests, $t(28)<2.08$, except for the SOA central cue of -300 msec with peripheral onset of $80 \mathrm{msec}, t(28)=2.63$ ], suggests that a peripheral onset at a nonattended location does not affect performance when attention is focused prior to display onset. The overall error rates were $2.5 \%, 2.0 \%$, and $2.1 \%$ for central cue SOAs of $-600,-300$, and $200 \mathrm{msec}$, respectively.

Since it was recently suggested (Warner, Juola, \& Koshino, 1990) that extensive practice can reduce the automatic attention capture by abrupt onsets, an additional analysis was conducted in which the nine sessions of 160 trials each were divided into three separate blocks of 480 trials each. For each central SOA condition, separate ANOVAs were run with factors of peripheral onset SOA, trial type, and trial block. As expected, practice produced a main effect of trial block in each analysis. However, this factor was not involved in any interaction, suggesting that practice did not change the attention-attraction properties of the abrupt onset.

\section{Discussion}

The results clearly failed to show an effect of abrupt onset at nonattended locations, which confirms the results of Yantis and Jonides (1990). As is evident from Figure 2, attentional focusing prior to display onset (central cue
SOAs of -600 and -300 msec) eliminated attentional capturing of the peripheral onset at nontarget locations. However, attentional capturing was apparent when prior focusing was not possible (central cue SOA of $200 \mathrm{msec}$ ). Figure 2 (right panel) shows that for the central cue SOA 200 -msec condition, attention was captured by the abrupt onset. When the onset appeared near the target location, responses were faster than in the control condition; when the onset appeared near a nontarget location, responses were slower than in the control condition. The finding of costs and benefits relative to the control condition suggests that search consistently started at the location of the abrupt onset. When this location contained the target, responses were fast; when this location contained a nontarget, responses were relatively slow.

On the other hand, when attention was focused prior to display onset, a peripheral onset at a nontarget location did not affect performance at all: RTs for these conditions were identical to the RT of the control condition. Since focusing precludes attention capturing, abrupt onsets do not satisfy the intentionality criterion of automaticity. Contrary to the claim of the strong automaticity hypothesis (e.g., Müller \& Rabbitt, 1989), the present study shows that the extent to which abrupt onsets capture attention is under the control of the subject's intentions rather than under the control of stimulation, a conclusion similar to that of Yantis and Jonides (1990). In addition, presenting an abrupt onset near a nontarget location during endogenous focusing (peripheral onset SOAs of -160 and $-80 \mathrm{msec}$ ) does not disrupt processing. The presentation of an abrupt onset near a nontarget location during processing of the target (peripheral onset SOA of $80 \mathrm{msec}$ ) does not affect performance either. Hence, the previously raised limiting factor of the procedure of Yantis and Jonides (1990) concerning simultaneous onset and offset proved not to be tenable.

The present experiment extends previous findings in that abrupt onsets do interfere when occurring within the attended area. As is clear from Figure 2 (left and middle panel), large interference effects are found when an abrupt onset is presented in close temporal proximity to display onset. The large effect at the peripheral onset SOA of 0 msec suggests that the offsets of the camouflaging line segments at the attended location cannot prevent attention being distracted by the peripheral onset. When the abrupt onset occurs $160 \mathrm{msec}$ before display onset, the interference effect caused by the abrupt onset is eliminated.

Together, these results suggest that the extent to which abrupt onsets interfere depends on the size of the spotlight. Within the spotlight of attention, abrupt onsets do interfere. The central cue enables subjects to change the size of the spotlight from unfocused covering of the entire field to a state in which attention is focused on a specific location.

\section{EXPERIMENT 2}

Experiment 1 showed that within the spotlight of attention, a peripheral abrupt onset attracts attention despite 
the presence of competing offsets of the camouflaging line segments. Even an offset at the attended location could not prevent attention from being captured by the nearby peripheral onset. This result is consistent with Jonides and Yantis's conclusions (1988) that onset transients are unique in their ability to attract attention. Recently, however, Miller (1989) has suggested that any abrupt change in the visual field is capable of attracting attention, a conclusion that has been supported by Theeuwes (1990). In addition, psychophysical studies have shown that subjects are sensitive to abrupt onset as well as offset (e.g., Breitmeyer \& Ganz, 1976). Miller (1989) has shown that the effect of abrupt onset in attracting attention attenuates when nontargets contain more offsetting line segments. Miller concluded that attention was controlled by the total display change rather than exclusively by abrupt onsets.

It should be noted that Miller's (1989) conclusion that offsets have some power to attract attention is based on the demonstration that onset capability to attract attention is reduced when the background contains sufficient offset transient distractors. Hence, there is no direct evidence that offset transients are capable of attracting attention to a location in the visual field.

Experiment 2 was designed to investigate this issue. Together with the premasks, four peripheral line segments were presented at all four locations. At variable SOAs, one of the line segments was abruptly switched off, causing a nonsymmetrical offset in the visual field. As in Experiment 1 , three different central cue SOA conditions were used in order to explore the effect of visual offsets in various endogenous cue conditions.

\section{Method}

Task, Stimuli, and Apparatus. The task, the stimuli, and the equipment were the same as in the previous experiment.

Subjects. Twenty-four new subjects ranging in age from 17 to 27 years participated in the experiment. Random groups of 8 subjects were assigned to each of the central SOA conditions. All had normal or corrected-to-normal vision, were right-handed, and were paid for participation.
Experimental Design and Procedure. The procedure and design were identical to those of the previous experiment. Because practice did not alter any of the effects, the subjects performed six instead of nine experimental sessions.

\section{Results and Discussion}

Figure 3 shows the mean RTs for correct responses as a function of peripheral offset SOA. The ANOVA for the central SOA 200-msec condition showed reliable effects for peripheral SOA $[F(3,21)=4.8, p<.01]$ and trial type $[F(1,7)=62.0, p<.01]$. The interaction between these variables was also significant $[F(3,21)=12.1$, $p<.01]$. Again, conditions in which the offset occurs at target location clearly before display onset (peripheral SOAs of -160 and $-80 \mathrm{msec}$ ) differed significantly from the control condition [Dunnett's $t$ tests, $t(28)>4.98$, $p<.01]$. When the offset occurred at a nontarget location, the SOA -160 -msec condition differed reliably from the control $[t(28)=3.35, p<.01]$. Together, these results show that an offset is capable of attracting attention to a location in the visual field.

For the central cue SOAs of -600 and $-300 \mathrm{msec}$, none of the factors manipulated was significant, suggesting that neither an offset at the nonattended location nor an offset at the attended location produces interference. Although the SOA 200-msec condition demonstrated the capability of offsets in attracting attention, these results suggest that prior focusing of attention on a location eliminates attention attraction of all peripheral offsets. The error rates were $2.0 \%, 2.4 \%$, and $1.8 \%$, for central cue SOAs of $-600,-300$, and $200 \mathrm{msec}$, respectively.

An analysis across the two experiments revealed that in conditions in which attention could not be focused in advance (central cue SOA of $200 \mathrm{msec}$ ), visual offsets were as effective as visual onsets in attracting attention since there was no significant effect of the factor onset versus offset; nor did this factor interact with any of the other variables. A comparison of the conditions in which attention was focused prior to display onset (central SOA

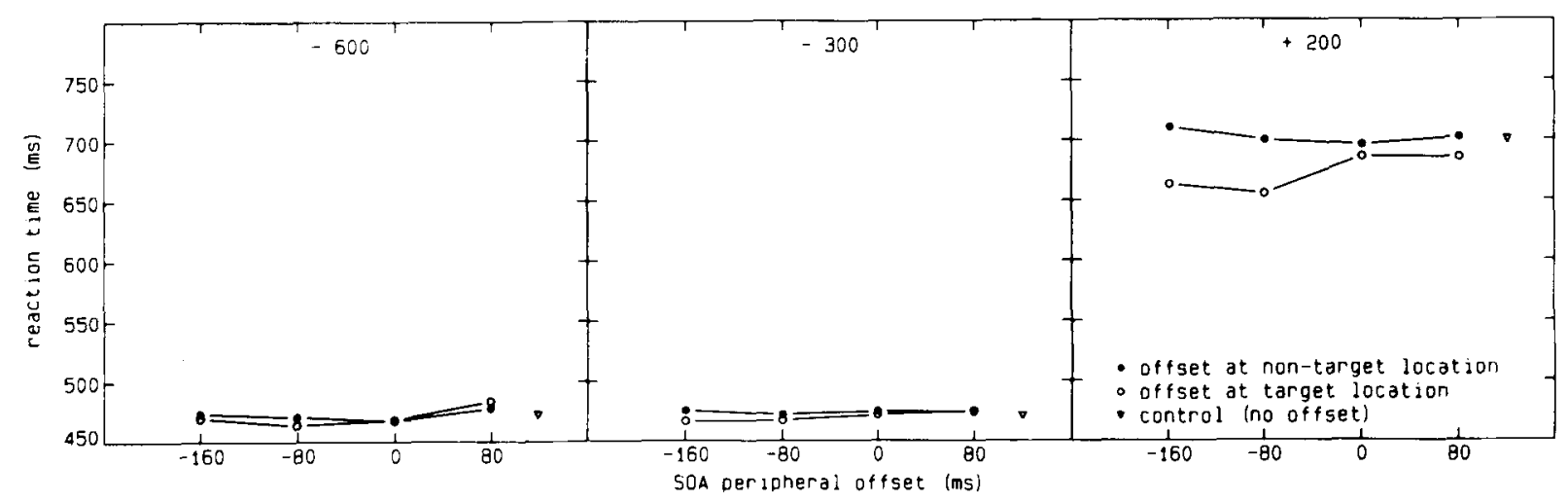

Figure 3. Mean reaction time for different trial types (offset near nontarget, offset near target, control) as a function of peripheral offset-to-display SOA for the central cue-display intervals of $-600 \mathrm{msec}$ (left panel), $-300 \mathrm{msec}$ (middle panel), and $200 \mathrm{msec}$ (right panel). 
conditions of -600 and $-300 \mathrm{msec}$ ), shows a significant interaction between onset versus offset and trial type [central cue SOA of $-600 \mathrm{msec}, F(1,14)=75.5, p<.01$; central cue SOA of $-300 \mathrm{msec}, F(1,14)=41.6, p<.01]$, suggesting that the effects of an onset near the attended location are quite different from the effects of an offset.

\section{GENERAL DISCUSSION}

Both experiments show that when attention is unfocused, it is drawn to a region in the visual field containing a visual onset or offset. The delays due to visual onset and offset are quite comparable, suggesting that visual offsets are as effective as visual onsets in attracting attention to a location in space.

When attention is focused prior to display onset, visual on- or offset transients presented at nonattended locations do not interfere. This result indicates that by voluntary focusing, the attention-attraction effect of peripheral onsets and offsets can be eliminated. Since attention capture by peripheral onsets or offsets is subject to voluntary control, these transients do not satisfy the intentionality criterion for automaticity. The present findings confirm and extend the conclusions of Yantis and Jonides (1990).

The finding that only onsets-and not offsets-produce interference near the attended location seems puzzling, especially because the on- and offset transients behave similarly when attention operates in an unfocused mode of processing. There are at least two possible solutions to this apparent puzzle. One is that the bar marker presented near the target letter produces lateral masking in the sense of adverse interactions between line segments (see, e.g., Bouma, 1978). This account seems particularly viable because adverse interactions are thought to occur at the retinal eccentricities presently used. Yet the data suggest that this type of masking does not occur; when the bar marker is presented well before display onset (SOA, $-160 \mathrm{msec})$, it does not produce any interference whatsoever. Obviously, a feature-interaction explanation of lateral masking cannot account for effects that depend on the temporal proximity between target and bar marker. A second possible account is a lateral interference explanation in terms of perceptual grouping and/or distribution of attention (see, e.g., Wolford \& Chambers, 1983). According to this view, the distribution of attention depends on factors such as grouping, number of items within a group, and spatial location. The present results suggest that the distribution of attention is also dependent on the temporal proximity between the target and the masking stimulus. In Experiment 1, when the bar marker was presented in close temporal proximity to display onset (SOAs of 0 and $80 \mathrm{msec}$ ), the target and bar marker were more likely to be perceived as a single perceptual object, implying that some attention was drawn away from the target and/or had to be shared by a larger perceptual object. Presenting the bar marker well before display onset might enable refocusing of attention to the target. Obviously, in the case of a visual offset, the sharing of atten- tion does not occur, and all processing resources can be directed to the target.

There exists a large difference in absolute RTs between the conditions in which attentional focusing was possible (central cue SOAs of -600 and $-300 \mathrm{msec}$ ) relative to the condition in which this was not possible (central cue SOA of $200 \mathrm{msec}$ ). This finding is consistent with the zoom-lens theory, since concentrating attention on a small field of view is thought to increase the processing power at that location and lead to relatively fast RTs. Yet Yantis and Jonides's (1990) results were different in this respect. Their Experiment 2 showed that when the central cue was not available before display onset, responses to an item having abrupt onset were as fast as responses to a target located at the position focused before display onset. This finding suggests that attention capturing by a peripheral onset is as effective as prior attentional focusing, a result that is at odds with the present study. The reason for this discrepancy might be that onset in Yantis and Jonides's study (1990) was a moderately reliable cue $(50 \%)$ for the target, since on half of the trials the target had abrupt onset while three nontargets were of the no-onset type. Attending the onset item was an efficient strategy, since it was the target on half of the trials. This manipulation limits Yantis and Jonides's findings, because it is hard to justify the claim that attention was automatically and unintentionally captured by the onset stimulus.

In the present study, there was no benefit in attending to the abrupt transient since the peripheral onset was randomly associated with the location of the target. Previous studies have demonstrated that, given such a statistical structure, subjects tend to match their performance with the precise statistical structure of the task; they tend to equalize performance across all locations. Thus, Jonides and Yantis (1988) found that subjects equalized performance across all items when an item with a unique color or intensity had no higher probability of being the target than did any other item. In line with a standard serial search model, all the items in the display were treated identically. Yet, employing the same statistical task structure, Jonides and Yantis (1988) demonstrated that an item with abrupt onset was always processed first, regardless of its identity or position. In other words, if incompatible with the statistical structure of the task, search invariably starts at a specific item, and then, it has been argued, attention is captured by the specific item. In the conditions with SOAs of $200 \mathrm{msec}$ in Experiments 1 and 2, exactly this was demonstrated; search always started at an item near the onset and offset stimulus even when this item had no higher chance of being the target than any other item in the display. Although the stimulus event was an irrelevant display change, attention was always shifted first to the location containing the visual change. Therefore, in line with previous studies (e.g., Jonides \& Yantis, 1988; Yantis \& Jonides, 1990), it can be concluded that when attention is broadly distributed, both abrupt onsets and offsets do attract attention even when there is no benefit to do so. 
Yet these findings do not suggest that attention is captured by the peripheral event against the subject's intentions. When attending to the peripheral event is harmful for the task, the attention-capturing power of a peripheral event might be reduced. The present study, together with that of Yantis and Jonides (1990), suggests that such a reduction might be obtained by advance focusing of attention on a location in the visual field. Some recent studies have demonstrated that subjects are able to suppress the attention attraction exerted by visual onsets. Warner et al. (1990) showed that, after extended practice, subjects were able to circumvent attentional capture by a peripheral onset. In addition, Lambert, Spencer, and Mohindra (1987) instructed subjects to avoid attending to a peripheral onset. Their results showed that this instruction reduced the attention-capturing power of the peripheral onset significantly. They concluded that orienting attention to a peripheral event is automatic in the sense that orienting will be executed unless there are explicit instructions to the contrary.

In conclusion, then, in an unfocused state, attention covers the entire visual field, which suggests that abrupt onsets and offsets do attract attention similarly. When an endogenous cue enables one to "zoom in" on a particular area, abrupt transients clearly outside the circumscribed area cease to attract attention. In line with the zoom-lens theory of attention, such a result is expected, since focusing results in tunnel vision of the "internal eyeball" (Eriksen \& Yeh, 1985). In a focused mode of attention, abrupt onsets near the attended location tend to draw attention away from the target, whereas no such interference is found with abrupt offsets.

\section{REFERENCES}

BoumA, H. (1978). Visual search and reading: Eye movements and functional visual field. A tutorial review. In R. Requin (Ed.), Attention and performance VII (pp. 115-146). Hillsdale, NJ: Erlbaum.

BREITMEYER, B. C., \& GANZ, L. (1976). Implications of sustained and transient channels for theories of visual pattern masking, saccadic suppression, and information processing. Psychological Review, 83, 1-36.

BROADBENT, D. E. (1982). Task combination and selective intake of information. Acta Psychologica, 50, 253-290.

Eriksen, C. W., \& Hoffman, J. E. (1973). The extent of processing of noise elements during selective encoding from visual displays. Perception \& Psychophysics, 14, 155-160.

ERIKSEN, C. W., \& YEH, Y.-Y. (1985). Allocation of attention in the visual field. Journal of Experimental Psychology: Human Perception \& Performance, 11, 583-597.

JoNiDEs, J. (1981). Voluntary vs. automatic control over the mind's eye's movement. In J. B. Long \& A. D. Baddeley (Eds.), Attention and performance $I X$ (pp. 187-203). Hillsdale, NJ: Erlbaum.

Jonides, J., Naveh-Benjamin, M., \& Palmer, J. (1985). Assessing automaticity. Acta Psychologica, 60, 157-171.

JoNIDES, J., \& YANTIS, S. (1988). Uniqueness of abrupt visual onset in capturing attention. Perception \& Psychophysics, 43, 346-354.
Kahneman, D., \& Treisman, A. (1984). Changing views of attention and automaticity. In R. Parasuraman \& D. R. Davies (Eds.), Varieties of attention (pp. 29-61). New York: Academic Press.

LABERGE, D. (1981). Automatic information processing: A review. In J. B. Long \& A. D. Baddeley (Eds.), Attention and performance $I X$ (pp. 173-186). Hillsdale, NJ: Erlbaum.

Lambert A., SPEnCER, E., \& Mohindra, N. (1987). Automaticity and the capture of attention by a peripheral display change. Current Psychological Research \& Reviews, 6, 561-594.

MiLleR, J. (1989). The control of attention by abrupt visual onsets and offsets. Perception \& Psychophysics, 45, 567-571.

Müller, H. J., \& Findley, J. M. (1988). The effect of visual attention on peripheral discrimination thresholds in single and multiple element displays. Acta Psychologica, 69, 129-155.

MüLlER, H. J., \& RABBITT, P. M. A. (1989). Reflexive and voluntary orienting of visual attention: Time course of activation and resistance to interruption. Journal of Experimental Psychology: Human Perception \& Performance, 15, 315-330.

NeumanN, O. (1984). Automatic processing: A review of recent findings and a plea for an old theory. In W. Prinz \& A. F. Sanders (Eds.), Cognition and Motor Processes (pp. 255-290). Berlin: Springer-Verlag.

PosNer, M. I. (1980). Orienting of attention. Quarterly Journal of Experimental Psychology, 32, 3-25.

Posner, M. I., SNyder, C. R. R., \& Davidson, B. J. (1980). Attention and the detection of signals. Journal of Experimental Psychology: General, 109, 160-174.

TheEUWES, J. (1990). Perceptual selectivity is task dependent: Evidence from selective search. Acta Psychologica, 74, 81-99.

TODD, J. T., \& VAN GELDER, P. (1979). Implications of a sustainedtransient dichotomy for the measurement of human performance. Journal of Experimental Psychology: Human Perception \& Performance, $5,625-638$.

WARNer, C. B., Juola, J. F., \& Koshino, H. (1990). Voluntary allocation versus automatic capture of visual attention. Perception \& Psychophysics, 48, 243-251.

Wolford, G., \& Chambers, L. (1983). Lateral masking as a function of spacing. Perception \& Psychophysics, 33, 129-138.

YanTIS, S., \& Jonides, J. (1984). Abrupt visual onsets and selective attention: Evidence from visual search. Journal of Experimental Psychology: Human Perception \& Performance, 10, 601-621.

YANTIS, S., \& JoNIDES, J. (1990). Abrupt visual onsets and selective attention: Voluntary versus automatic allocation. Joumal of Experimental Psychology: Human Perception \& Performance, 16, 121-134.

\section{NOTES}

1. Although it is realized that an exact time estimation of detection and identification of gradual onset stimuli is difficult (Yantis \& Jonides, 1990), this procedure was chosen to prevent the central cue from disrupting processing. For the analysis of the time course of activation of the exogenous onset, the exact timing of identification of the central cue is not critical, especially because the central cue reaches its full intensity well before or well after the presentation of the exogenous onset.

2. It is recognized that the cue-display intervals used do not preclude the possibility of eye movements toward the cued location. However, in similar studies (e.g., Müller \& Rabbitt, 1989), it has been shown that subjects seldom make eye movements and that they maintain fixation reliably when this is required. A similar argument has been made by Yantis and Jonides (1990).

(Manuscript received February 1, 1990; revision accepted for publication July 18,1990 .) 